\title{
Régimen Jurídico-Administrativo de la tutela asistencial de menores y de los Centros de Protección ${ }^{1}$
}

\author{
María Luisa Roca Fernández-Castanys \\ Profesora Contratada Doctora de Derecho administrativo \\ Universidad de Almería
}

\begin{abstract}
SUMARIO: 1. INTRODUCGIÓN; 2. LOS MECANISMOS DE PROTEGCIÓN DE LOS MENORES: TUTELA AUTOMÁTICA VERSUS GUARDA: 2.1. El desamparo como concepto jurídico indeterminado; 2.2. Los presupuestos del desamparo: a) Elemento objetivo: la desprotección del menor; b) Elemento subjetivo: incumplimiento de los deberes de protección; c) Nexo causal.; 3. EL ACOGIMIENTO RESIDENCIAL: 3.1. Consideraciones previas; 3.2. Los centros de protección de menores; 3.2.1. Concepto, clases y requisitos; 3.2.1.1. Concepto; 3.2.1.2. Clases; 3.2.1.3. Requisitos: A. Materiales; B. Funcionales; C. Requisitos previos: la autorización y la inscripción; D. La habilitación y el convenio de colaboración; a) La habilitación; b) El convenio de colaboración; 4. RÉGIMEN SANCIONADOR: 4.1. La inspección de los centros; 4.2. Infracciones y sanciones. 5. REFLEXIÓN FINAL. BIBLIOGRAFÍA CITADA.
\end{abstract}

\section{INTRODUCCIÓN}

En España existen en la actualidad entre 33.000 y $38.000^{2}$ niños tutelados por la Administración Pública, ostentando nuestro país el dudoso honor de li-

\footnotetext{
${ }^{1}$ Este artículo se realiza en el marco del proyecto de investigación del MICI "Políticas Jurídicas sobre el menor" (SEJ 2007-67096), del que es Investigadora Principal, la Pfra. Dra. Ma Belén Sáinz-Cantero Caparrós, Profesora de la UAL.

${ }^{2}$ No existen datos exactos sobre el número de menores tutelados. Precisamente, una de las principales denuncias de los agentes implicados en la protección de menores, es la falta de una información estadística actualizada y fidedigna al respecto. A tal fin, el Informe de la Comisión Especial del Senado para el Estudio de la problemática de la adopción nacional y otros temas afines (2010), propone la implantación a nivel nacional de un Sistema de evaluación y registro en acogimiento residencial (SERAR), como instrumento fundamental para el seguimiento individualizado de cada menor (este Informe está publicado en el BOCG-S, de 17 de noviembre de 2010, pág. 52).
} 
derar el número de menores institucionalizados en Europa occidental ${ }^{3}$. Las precarias condiciones de vida de los menores ingresados en alguno de estros centros se pusieron en evidencia hace unos años a raíz un Informe especial del Defensor del Pueblo ${ }^{4}$ en el que se denunciaba una "realidad extremadamente dura, dolorosa y compleja" que, según apunta, alcanza "límites inesperados". A lo largo de sus casi cuatrocientas páginas, el lector asiste, sobrecogido, a la constatación de una realidad que resulta tanto más dolorosa por cuanto sus víctimas son aquéllos "que no pueden gritar"5. Los datos que ofrece exigen respuesta inmediata en la que, como no podía ser de otra manera, los poderes públicos y, en particular, la Administración, deben jugar un papel fundamental ${ }^{6}$.

Las reflexiones que preceden justifican el por qué de este trabajo. La concreción del marco jurídico de los centros de protección de menores resulta imprescindible para saber si existen en nuestro país los resortes adecuados para la debida protección de los intereses de este frágil colectivo. El propósito de esta investigación es analizar su régimen jurídico-administrativo dejando a un lado otros problemas que encuentran su sede en otras ramas del Derecho como el

3 Diario "El País "de 18 de julio. Disponible en su versión digital en: http://www.elpais.com/articulo/sociedad/Senado/propone/sacar/pequenos/centros/tutelados/elpepisoc/20101018elpepisoc_2/Tes

${ }^{4}$ Defensor del Pueblo (2009), Informes, Estudios y Documentos. Centros de protección de menores con trastornos de conducta y en situación de dificultad social. Disponible a texto completo en

http://www.defensordelpueblo.es/es/Documentacion/Publicaciones/monografico/Documentacion/centros menores problemas conducta.pdf

${ }^{5}$ Tal fue la gráfica expresión utilizada por el portavoz del Grupo Socialista, Sr. Valls García, en su intervención en la Comisión de Justicia e Interior que debía debatir el Proyecto de Ley de protección del menor (DSCD núm. 593, de 18 de octubre de 1995, pág. 18081)

${ }^{6}$ Como señaló el Defensor del Menor de Andalucía en su Informe Especial Sistema de protección de menores y acogimiento residencia. Tomo I (1999), "las Administraciones tienen la responsabilidad de liderar las actuaciones encaminadas a la protección de los menores y preservarlos de los estados de fragilidad familiar y social; deben promover conductas sociales e institucionales orientadas en beneficio del correcto desarrollo de los menores; y deben destinar el máximo de los recursos de que dispongan en lograr la efectividad de los derechos económicos, sociales y culturales de los niños". Este informe está disponible a texto completo en la URL: http://www.defensor-and.es/informes y publicaciones/informes estudios y resoluciones/informes defensor del menor/informe $0000 /$ descargas/TOMO1.DOG.

Sobre el papel de las Administraciones Públicas en la protección de menores, vid. DE PALMA DEL TESO, A. (2004): "El derecho de los menores a la asistencia y protección de las Administraciones Públicas. Las competencias locales en materia de protección de menores”, Cuadernos de Derecho Local núm. 4, págs.103-138. 
civil, el penal o el procesal. Por lo demás, una elemental prudencia científica aconseja -habida cuenta la proliferación normativa presente en esta materialimitar el análisis al ámbito andaluz, sin perjuicio de las ineludibles referencias al ordenamiento estatal ${ }^{7}$.

\section{LOS MECANISMOS DE PROTECCIÓN DE LOS MENORES: TUTELA AUTOMÁTICA VERSUS GUARDA}

A la hora de abordar el estudio de esta materia es preciso hacer una primera constatación, y es que no puede olvidarse -como reiteradamente ha puesto de manifiesto la doctrina- que la actuación de la Administración en este ámbito es residual o subsidiaria ${ }^{8}$ ("ultima ratio"), es decir, se trata de una actuación "in extremis" en cuanto los mecanismos públicos de protección se activan cuando fallan o no funcionan adecuadamente los resortes "naturales".

${ }^{7}$ A la fecha de redacción de este trabajo se está discutiendo la reforma de la legislación de protección de menores, encontrándose en tramitación sendos anteproyectos que introducen importantes novedades en las principales leyes estatales en la materia, a saber, La Ley orgánica 1 /1996, de 15 de enero de protección jurídica al menor, el Código Civil, la Ley Orgánica del Poder Judicial, y la Ley de Enjuiciamiento Civil.

${ }^{8}$ Declarada la situación de desamparo, la Administración debe adoptar las medidas que sean precisas para proteger a los menores con la mayor celeridad.

Desde este punto de vista, algunos autores afirman que la intervención de la Administración "no es subsidiaria", porque debe actuar necesariamente (así, vid. VARGAS CABRERA, B. (1994): La protección de menores en el ordenamiento jurídico. Comares, Granada). Sin embargo, debe puntualizarse que cuando se dice que la actuación de la Administración es subsidiaria, debe entenderse que se hace referencia a que ésta sólo entra en juego cuando los demás mecanismos fallan. En caso de que existiese familia extensa que pudiera hacerse cargo del menor desamparado, no procederá la asunción de la tutela por la Administración, sino el llamamiento del familiar obligado conforme a las reglas de la tutela ordinaria, pues como señala el art. 239 del Cc.: "La tutela de los menores desamparados corresponde por Ley a la entidad a que se refiere el artículo 172. Se procederá, sin embargo, al nombramiento de tutor conforme a las reglas ordinarias, cuando existan personas que, por sus relaciones con el menor o por otras circunstancias, puedan asumir la tutela con beneficio para éste".

${ }^{9}$ El papel del Estado como garante último de los derechos de los menores se ha puesto de manifiesto por SÁINZ-CANTERO CAPARRÓS, Ma B. y PARDO MARTÍNEZ, E. (2010): Régimen jurídico de los centros de protección y reforma de menores. Comares, Granada, págs. 10 y 22. Por su parte, el papel de la familia como institución al servicio de sus miembros se destaca por ALEMÁN BRACHO, C. (2005), en su artículo "La familia, prestadora y destinataria de prestaciones", Documentación Administrativa núm. 271-272, pág. 241. Vid. también VIVANCOS SÁNCHEZ, M. (2001), “Constitución de la tutela automática” (Ref. La Ley 1959/2001): pág. 1. 
Partiendo de esta idea, resulta que el Código Civil (en adelante, Gc) no diferencia con nitidez los distintos regímenes de protección de los menores ${ }^{10}$. En efecto, la sección $1^{\text {a }}$ del capítulo V, del Título VII del Libro Primero, induce a confusión en cuanto su título es "De la guarda y acogimiento de menores", ya que, además de la guarda y el acogimiento, regula también la tutela, con lo cual se acaba mezclando lo que son regímenes de protección (tutela y guarda) con lo que son medidas de protección (acogimiento e internamiento).

En una rápida aproximación al tema y con entera independencia de lo que después, a mayor abundamiento, se dirá, puede afirmarse que la tutela $e x$ lege procede respecto de aquéllos menores que se encuentran en situación de desamparo, mientras que la guarda aparece prevista para cuando quienes tienen potestad sobre el menor justifiquen no poder atenderlo por alguna circunstancia grave o cuando así lo acuerde un juez ${ }^{11}$ Tras la reforma del art. 172 del Cc por la Ley Orgánica 1/1996, de 15 de enero, de Protección Jurídica del Menor (en lo sucesivo, LPOM) desaparece ${ }^{12}$ la distinción que se recogía en su apartado segundo - a la hora de solicitar la constitución de la guarda- entre "enfermedad u otras circunstancias graves" y que, con razón, tan criticada había sido por algún autor ${ }^{13}$

${ }^{10}$ Esta falta de precisión se ha denunciado por diversos autores, así, entre otros, EGEA FERNÁNDEZ, J. (1993), "Comentario al artículo 173 del Código Civil", en BERCOVITZ RODRÍGUEZ-CANO, R (Coord.), Comentarios a las reformas del Código Civil. Tecnos, Madrid, pág. 88; RODRÍGUEZ SOL, L., (1993), "La protección y acogimiento de menores en el Derecho español”, (Ref. La Ley 13787), pág. 9 o BENITO ALONSO, F. (2001): "Actuaciones frente a situaciones de riesgo y desamparo de menores: tutela por ministerio de la Ley y guarda" (Ref. La Ley 11848/2001).

${ }^{11}$ De los datos reflejados en el Boletín Estadístico de Protección a la Infancia 2009, elaborado por la Dirección General de Familias y la Infancia, resulta que el número y tasa de niños bajo tutela varía mucho de unas comunidades autónomas a otras. La tasa nacional de niños tutelados es de 382 por cada cien mil menores de 18 años. Ceuta y Melilla se encuentran muy por encima de la media nacional, seguidas de Murcia, Cataluña, Asturias y Andalucía que, a pesar de estar por encima de la media, tienen una tasa más moderada. En el extremo opuesto se encuentran la Navarra, Aragón, Castilla y León, Extremadura y Castilla La Mancha que no llegan a una tasa de 220 por cien mil.

${ }^{12}$ Es el caso de Andalucía. Vid. art. 37.1 del Decreto 42/2002, de 12 de febrero (BOJA núm. 20, de 16 de febrero), que regula el Régimen de desamparo, tutela y guarda administrativa en esta Comunidad.

${ }^{13}$ Cfr. LLEBARÍA SAMPER, S. (1990): Tutela automática, guarda y acogimiento de menores. Bosch, Barcelona, pág. 77 y ss. 
La tutela presupone la guarda, es decir, desde el momento en que se constituye, el ente público asume las funciones que integran la patria potestad (art. $172.1 \mathrm{Cc})$. En cambio, la guarda no implica aquélla, pues, en este caso, el ente público asume únicamente el ejercicio de las funciones personales respecto del menor, pero no su tutela ${ }^{14}$. Dicho de otro modo: en la guarda se confía transitoriamente a la entidad pública el ejercicio de los poderes paternos, pero sin sustituirlos. Pero eso no es todo, tutela automática y guarda conllevan la adopción de medidas de distinto grado e intensidad ${ }^{15}$, lo que justifica deban deslindarse cuidadosamente los supuestos en los que proceden. En esta labor, podrá comprobarse que el desamparo ${ }^{16}$ aparece como concepto clave que conviene analizar con detenimiento. Veámoslo.

\subsection{El desamparo como concepto jurídico indeterminado}

El artículo 172 C. caracteriza el desamparo ${ }^{17}$ como la situación que se produce "de hecho a causa del incumplimiento, o del imposible o inadecuado ejercicio de los deberes de protección establecidos por las leyes para la guarda de los menores cuando éstos queden privados de la necesaria asistencia moral o material". A sensu contrario, no hay desamparo sino simple "riesgo" ${ }^{18}$ cuando

${ }^{14}$ Como señala LLEBARÍA SAMPER, S. (1990), pág. 95 "no debe confundirse lo que es la titularidad de la guarda -asumida conforme al art. 172.1 o 2- con lo que supone el ejercicio de la misma (...). Por tanto, estamos examinando cómo se ejerce la guarda de la que ya es titular la entidad pública, bien por quedar aquélla embebida en el cargo tutelar que asume con respecto del menor desamparado (art. 172.1), bien por serle solicitada y conferida dicha guarda por quien proceda, u ordenada por el juez (172.2)".

15 DE PALMA DEL TESO (2004), pág. 105 habla de "subsidiariedad progresiva".

${ }^{16}$ Sobre el concepto de desamparo, vid. BENITO ALONSO, F. (2001).

${ }^{17}$ Como precisa, entre otras, la SAP de Baleares 111/2005 de 11 marzo (Ponente Ilmo. Sr. D. Carlos Gómez Martínez) el concepto de desamparo es gramaticalmente más amplio que el anterior de "abandono", lo que confiere al órgano administrativo mayores posibilidades interpretativas.

${ }^{18}$ La Exposición de Motivos de la LOPM califica esta distinción de "innovadora", de manera que riesgo y desamparo dan lugar a un grado distinto de intervención de la entidad pública. En las situaciones de riesgo-caracterizadas por la existencia de un perjuicio para el menor que no alcanza la gravedad suficiente para justificar su separación del núcleo familiar- la intervención de la Administración se dirige a eliminar, dentro de la institución familiar, los factores que causan dicho perjuicio y que suponen un atentado al desarrollo personal o social del menor. En cambio, en las de desamparo, la gravedad de los hechos aconseja la extracción del menor de la familia, asumiendo la entidad pública la tutela del menor con la subsiguiente suspensión de la patria potestad ordinaria.

Sobre la protección de los menores en situación de riesgo, vid. MARTÍNEZ PIERA, E. (2010): "Reflexiones en torno a la intervención de los poderes públicos para la protección e inserción de los menores" (Ref. La Ley 7976/2010). 
existen carencias o dificultades en la atención de las necesidades básicas que los menores precisan para su correcto desarrollo físico, psíquico o social que no requieren su separación del medio familiar. Este concepto se introdujo por la LOPM, configurándose como una figura independiente de carácter preventivo $^{19}$ ya que, detectada la situación de riesgo, lo que procede es la adopción de las medidas que lo eliminen impidiendo que llegue a tornarse en desamparo, para lo cual la entidad pública competente pondrá en marcha las actuaciones pertinentes en la propia familia del a través de distintas medidas (económicas, formativas... ${ }^{20}$ ) realizando después el seguimiento de la evolución del menor ${ }^{21}$.

En consecuencia, a diferencia de las situaciones de riesgo, el desamparo se refiere a aquellas otras de gravedad bastante que justifican una intervención drástica para separar al menor - al menos temporalmente ${ }^{22}$ - del entorno fa-

${ }^{19} \mathrm{El}$ déficit de figuras preventivas de protección a los menores se destacó por la Sra. Ministra de Asuntos Sociales (Alberdi Alonso) en su comparecencia en el Congreso para analizar el Proyecto de LOPM (DSCD núm. 172, de 28 de septiembre de 1995).

${ }^{20}$ Como señala la SAP de Baleares 111/2005 de 11 marzo, en estos casos, "la entidad pública competente pondrá en marcha las actuaciones pertinentes para reducir la situación intentando eliminar los factores de riesgo actuando en la propia familia del menor a través de medidas de apoyo o ayuda familiar; medidas económicas, cuando la causa determinante de riesgo proceda de carencias o insuficiencias de recursos de esta clase; prestaciones de tipo formativo o psicosocial, con la finalidad de mantener el hogar familiar como soporte básico y facilitar su normal integración social; medidas técnicas, a través de actuaciones profesionales, para restablecer y facilitar el adecuado ejercicio de las funciones parentales, mejorando las relaciones socio-familiares y promoviendo el desarrollo y bienestar del menor".

${ }^{21}$ Vid. Art. 22.2 de la Ley 1/1998, de 20 de abril.

Dentro de las situaciones de riesgo podrían incluirse -con las diferencias derivadas de sus propias particularidades- los menores en situación de "conflicto social" entendiéndose por tales aquellas situaciones en las que a causa de la inadaptación grave de los menores éstos podrían llegar a causar perjuicios a sí mismos o a otras personas. En tales casos, como señalan SÁINZCANTERO CAPARRÓS, Ma B. y PARDO MARTÍNEZ, E. (2010), pág. 34, la Administración debe adoptar las medidas que permitan poner fin a la situación de inadaptación, marginación o exclusión social de estos menores pero "sin adoptar medidas de reforma" (ya que se trata de menores que no han cometido ningún ilícito penal). La opción preferente será, como señalan las autoras citadas, el mantenimiento del menor en su familia de origen o por lo menos, el acogimiento en una familia (con experiencia en el tratamiento de estos menores) sin que pueda descartarse el acogimiento residencial siempre que el centro cuente con otros menores de características similares, esté especializado y cuente con programas apropiados para su perfil.

22 Como hacen notar SÁINZ-CANTERO CAPARRÓS, Mª B. y PARDO MARTÍNEZ, E. (2010), pág. 28, "lo normal es que tal separación sea temporal, aunque en ocasiones puede ser definitiva porque se entienda que, atendidas las circunstancias personales, familiares y sociales del menor, lo más aconsejable sea la adopción del acogimiento familiar permanente o preadoptivo". 
miliar en que se halla con asunción de la tutela por parte de la entidad pública competente, haciendo tránsito - si así conviene a su interés- a su definitiva inserción en un núcleo familiar distinto al suyo. Con todo, el fin último que debe inspirar la actuación administrativa es el bienestar del menor, de manera que, una vez estabilizada y normalizada la situación familiar que provocó la declaración de desamparo, deberá procurarse su retorno a su familia sin que el hallazgo de una familia ideal se contraponga a la posibilidad de reinserción del menor en su familia original.

No obstante, la diferencia entre situación de desamparo y de riesgo no aparece siempre clara $-\mathrm{O}$, al menos, no tanto como sería conveniente- por lo que son los Tribunales los que, en última instancia, en un intento de reducir las zonas de penumbra y de hacer operativa la norma, quienes decidirán cuando estamos en presencia de una u otra ${ }^{23}$.

\subsection{Los presupuestos del desamparo}

De lo dicho hasta ahora ${ }^{24}$ puede deducirse que el desamparo es un concepto relativamente indeterminado cuyo grado de concreción vendrá dado en contemplación del análisis circunstanciado de cada caso concreto. Sin embargo, de lo dispuesto en el Cc, de las aportaciones doctrinales y del contenido de distintos pronunciamientos jurisprudenciales, pueden deducirse las notas que lo singularizan.

En primer lugar, no hay duda de que, tal y como aparece configurado en la actualidad, el desamparo es una situación de hecho [SAP de Baleares 111/2005, de 11 de marzo ${ }^{25}$; SAP Cantabria 52/2003, de 4 de febrero ${ }^{26}$; SAP de Valen-

Sobre los supuestos en los que puede estar justificada la prórroga del acogimiento, la constitución de la tutela ex lege o el retorno del menor con su familia, puede verse el trabajo de CORRAL GARCÍA, E. (2003): "El derecho a la integridad moral del menor como fundamento de la imposibilidad de la reinserción en su familia" (Ref. Aranzadi BIB 2003\1118).

${ }^{23}$ Así lo pone de manifiesto ESCRIBANO TORTAJADA, P. (2009): "Los conceptos de desamparo y situaciones de riesgo desde la perspectiva de nuestros tribunales" (Ref. La Ley 12141/2009), pág. 2.

24 Vid. DE PABLO CONTRERAS, P (1993): "Comentario al artículo 172 del Código Civil" ”, en BERCOVITZ RODRÍGUEZ-CANO, R. (Coord.), Comentarios a las reformas del Código Civil. Tecnos, Madrid, pág. 40 y ss. Vid. También ESGRIBANO TORTAJADA, P. (2009), pág. 2.

25 Ponente Ilmo. Sr. D. Carlos Gómez Martínez.

${ }^{26}$ Ponente, Ilmo. Sr. D. Javier de la Hoz de la Escalera El artículo 20 del Decreto 42/2002, de 12 de febrero, de Régimen de desamparo, tutela y guarda administrativa de Andalucía así lo recoge de forma explícita al señalar que "se considerará situación de desamparo la que se pro- 
cia 359/2004 de 7 junio $^{27}$ ] que, como tal, habrá de apreciarse por el órgano administrativo competente, y, por ende y a diferencia de la regulación anterior $^{28}$, sin necesidad de pronunciamiento judicial. Así caracterizado, el desamparo no presupone que el menor carezca de personas que ejerzan la patria potestad o tutela, pues, como se apuntó más arriba y se destaca por la doctrina ${ }^{29}$, los regímenes públicos de protección se activan, precisamente, cuando los mecanismos ordinarios fallan o no funcionan adecuadamente. Por tanto, el desamparo no procede únicamente respecto de los menores que carezcan de padres o tutores sino también, cuando teniéndolos, éstos no cumplan adecuadamente las funciones de protección que les corresponden.

Los requisitos para que una situación pueda calificarse de desamparo se reconducen a tres: a) uno objetivo: que el menor no tenga cubiertas sus necesidades mínimas (materiales y morales) conforme a niveles común y socialmente aceptados; b) otro subjetivo: que ello sea consecuencia del incumplimiento o inadecuado cumplimiento por parte de los progenitores o tutores de sus deberes de protección; y, finalmente, c) un nexo necesario entre el incumplimiento de los deberes de protección y la inasistencia material y/o moral al menor.

Veamos, brevemente, cada uno de los requisitos apuntados.

\section{a) Elemento objetivo: desprotección del menor}

El primero de los requisitos para que pueda hablarse de desamparo es la privación de la asistencia al menor. La jurisprudencia ha subrayado [Auto de la AP de Sevilla de 23 de noviembre de $1999^{30}$ ] que éste es el elemento deter-

duce de hecho a causa del incumplimiento o del imposible o inadecuado ejercicio de los deberes de protección establecidos por las leyes para la guarda de los menores, cuando éstos queden privados de la necesaria asistencia moral o material".

${ }^{27}$ Ilmo. Sr. D. José Enrique de Motta García-España

${ }^{28}$ Como aclara la SAP de Baleares (Sección 3 ${ }^{\mathrm{a}}$ ) 111/2005 de 11 marzo (Ponente Ilmo. Sr. D. Carlos Gómez Martínez), el antiguo abandono tenía la tacha de culpabilidad de quien abandonaba, requería resolución judicial y el transcurso de cierto lapso de tiempo. La reforma de 1987, pretende agilizar los procedimientos de protección al permitir la asunción automática de la tutela por parte de la entidad pública competente en los casos de grave desprotección.

${ }^{29}$ En este sentido, vid. ESPIAU ESPIAU, S. (1999): "La situación de desamparo y las medidas de protección", en ESPIAU ESPIAU, S. y VAQUER ALOY, A. (Eds.), Protección de menores, acogimiento y adopción. Marcial Pons, Madrid, pág. 77 y ss.

${ }^{30}$ Ponente IIma. Sra. María del Rosario Martín Rodríguez 
minante, puesto que el desamparo se concreta en un resultado: la desprotección del menor de edad. Es indiferente cuáles hayan sido las causas que la hayan provocado, de manera que se produce tanto si incide en la esfera material (alimentos) como en la esfera moral (afectividad o relaciones personales).

\section{b) Elemento subjetivo: incumplimiento de los deberes de protección}

En cuanto al elemento subjetivo, los deberes de protección a los que se viene haciendo referencia son los establecidos por las leyes para la guarda de los menores, es decir, los relativos a la esfera personal del menor que integran el contenido moral de la patria potestad (arts. 154 y 269 Cc), a saber: velar por el menor, tenerlo en su compañía, alimentarlo y educarlo procurándole una formación integral. Como se ha anticipado, el incumplimiento de tales deberes se produce no sólo en los casos de un abandono absoluto del menor - de manera que carezca de personas que se hagan cargo de él- sino que comprende también aquellos supuestos en que existiendo, incumplan sus deberes, los ejerzan inadecuadamente o están imposibilitados para llevarlos a cabo, siendo indiferente las circunstancias que provocan esta situación. [SAP de Baleares $111 / 2005$, de 11 de $^{2}$ arzo $^{31}$; SAP Cantabria 52/2003, de 4 de febrero ${ }^{32}$; Auto de la AP de Sevilla de 23 de noviembre de 1999³; Auto de la AP de Cádiz de 19 de mayo de $2001^{34}$ ].

\section{c) Nexo causal}

El último de los requisitos que vienen exigiéndose para que surja el desamparo es que la desprotección del menor sea consecuencia directa del incumplimiento de los deberes tuitivos de los representantes legales, con independencia de que dicho incumplimiento sea voluntario, involuntario o negligente [(SAP de Cantabria 52/2003, de 4 de febrero $\left.{ }^{35}\right)$ ]. De no venir originada la situación de privación de asistencia por la conducta incumplidora de los padres o guardadores, no resultarían de aplicación las previsiones del art. 172.1 C..

\footnotetext{
${ }^{31}$ Ponente Ilmo. Sr. D. Carlos Gómez Martínez.

32 Ponente, Ilmo. Sr. D. Javier de la Hoz de la Escalera

33 Ponente IIlma. Sra. María del Rosario Martín Rodríguez

${ }^{34}$ Ponente Ilmo. Sr. José Ma Pacheco Aguilera.

35 Ponente, Ilmo. Sr. D. Javier de la Hoz de la Escalera.
} 
Dicho esto, debe puntualizarse que el desamparo no es un concepto cerrado que pueda determinarse apriorísticamente. El propio interés del menor aconseja que así sea. Precisamente la conveniencia de no cerrar la puerta a una actividad protectora de la Administración - atada en sus posibilidades de actuación por una enumeración cerrada - fue el motivo que impidió que, en el proceso de discusión de la LOPM, prosperara la enmienda del Grupo Federal IU-IC en la que se proponía una enumeración de las situaciones de desamparo ${ }^{36}$. Como ha resaltado el Defensor del Pueblo, es preciso adoptar un punto de vista flexible admitiendo la posibilidad de que ésta se produzca aún cuando no esté presente alguno de los elementos anteriormente apuntados ${ }^{37}$.

${ }^{36}$ En particular, el texto de esta enmienda-la número 17 (BOCG núm. 117, de 22 de septiembre), pág. 31- era el siguiente "Se considerará situación de desamparo. a) Guando falten las personas físicas o jurídicas a las cuales por ley corresponde la responsabilidad parental o, cuando existiendo, estén imposibilitadas para ejercerla o en situación de ejercerla con grave riesgo para el menor; b) Cuando se aprecie cualquier forma de incumplimiento o de ejercicio inadecuado de la responsabilidad parental y de las obligaciones establecidas por la Ley que puedan afectar al desarrollo integral del menor; c) Cuando el menor presente signos de malos tratos físicos o psíquicos, abusos sexuales, explotación o cualesquiera otros de naturaleza análoga”

Con todo, algunas Comunidades Autónomas se resisten a no realizar una enumeración de supuestos. En el caso de Andalucía, el artículo 23 de la LMA recoge as siguientes: a) el abandono voluntario del menor por parte de su familia; b) la ausencia de escolarización; c) la existencia de malos tratos físicos o psíquicos o de abusos sexuales; d) la inducción a la mendicidad, delincuencia o prostitución o cualquier otra explotación económica del menor de análoga naturaleza; e) la drogadicción o el alcoholismo habitual del menor con el consentimiento o tolerancia de los padres o guardadores; f) el trastorno mental grave de los padres o guardadores que impida el normal ejercicio de la patria potestad o la guarda; $g$ ) la drogadicción habitual en las personas que integran la unidad familiar y, en especial, de los padres, tutores o guardadores del menor, siempre que incida gravemente en el desarrollo y bienestar del menor; h) la convivencia en un entorno social-familiar que deteriore gravemente la integridad moral del menor o perjudique el desarrollo de su personalidad; i) la falta de personas a las cuales corresponde ejercer las funciones de guarda o cuando éstas estén imposibilitadas para ejercerlas o en situación de ejercerlas con peligro grave para el menor.

Algunos autores consideran adecuada la enumeración de las causas que pueden dar lugar al desamparo habida cuenta del carácter excepcional de esta medida. En esta línea vid. MURILLAS ESCUDERO, J.M. (2003): "Notas a la Ley 4/1998, de 18 de marzo, del Menor, de la Comunidad Autónoma de la Rioja” (Ref. Aranzadi BIB 2003\418).

${ }^{37}$ Para el Defensor del Pueblo debe primar el análisis sociológico sobre la visión conceptualista, existiendo supuestos en los que, pese a no concurrir el elemento objetivo, debe entenderse que el menor se encuentra desamparado. Así ocurre, por ejemplo, si en el momento del nacimiento el personal del Centro Sanitario aprecia que los padres no reúnen las condiciones precisas para hacerse cargo del menor. En tal caso, aún no habiéndose producido de hecho la desprotección, la Administración podría iniciar el procedimiento que concluyese con la correspondiente declaración de desamparo. Vid., Defensor del Pueblo (2009), pág. 64. 
De apreciarse, la entidad pública no sólo estará autorizada sino legalmente obligada a declarar la situación de desamparo asumiendo, sin posibilidad de excusa, la tutela automática del menor ${ }^{38}$ y quedando en suspenso la patria potestad o tutela ordinaria, de manera que los padres o tutores quedarán provisionalmente privados de las facultades que les corresponden respecto de éste. Dicho de otro modo: apreciada la situación de desamparo - con la gravedad que comporta- el órgano administrativo - tras la correspondiente declaracióndeberá asumir la tutela del menor, con la consecuencia inmediata de que - al menos provisionalmente- los padres o tutores verán suspendidas sus funciones ${ }^{39}$.

En caso de urgencia, la Administración podrá adoptar, como medida cautelar, una "declaración provisional de desamparo", sin necesidad, por tanto, de esperar a la finalización del correspondiente procedimiento en que se declare formalmente ${ }^{40}$. Debe entenderse que esta suspensión se extiende tanto a los aspectos personales como patrimoniales, de manera que la potestad tuitiva del Ente público abarca tanto unos como otros

Antes de la reforma del artículo 172 Gc por la LOPM la doctrina había venido discutiendo si era lícito afirmar que la constitución de la tutela automática comportaba la suspensión de de la patria potestad o tutela ordinaria. Para DE PABLO CONTRERAS ${ }^{41}$, de ninguno de los preceptos del Código podía extraerse tal consecuencia. Sin embargo, en la actualidad, tras la citada reforma,

${ }^{38}$ En el caso de Andalucía, la competencia para apreciar y declarar la situación de desamparo corresponde a la Comisión Provincial de Medidas de Protección, órgano colegiado existente en cada una de las Delegaciones Provinciales de la Consejería de Igualdad y Bienestar Social de la Junta de Andalucía, ente público a quien corresponde la competencia en materia de menores en el ámbito territorial andaluz (vid. arts. 50 y 52 del Decreto 42/2002, de 12 de febrero, regulador del régimen de desamparo, tutela y guarda administrativa).

${ }^{39}$ Los múltiples problemas que se plantean en relación con la posible impugnación por los padres o tutores de la declaración de desamparo se han puesto de manifiesto por OCAÑA RODRÍGUEZ, A. (2005) en su trabajo "En busca de una más adecuada regulación del régimen de protección de menores" (Ref. La Ley 1808/2006).

${ }^{40}$ En Andalucía, el art. 32 del Decreto 42/2002, de 12 de febrero (BOJA núm. 20, de 16 de febrero), que regula el Régimen de desamparo, tutela y guarda administrativa en Andalucía, dispone que: "Cuando existan circunstancias que pongan en grave riesgo la integridad física o psíquica de los menores, se podrá declarar como medida cautelar, la declaración de desamparo por el titular de la Delegación Provincial de la Consejería competente en materia de protección de menores".

${ }^{41}$ DE PABLO CONTRERAS, P. (1993), pág. 38. 
la cuestión ha quedado zanjada no existiendo dudas de que la constitución de la tutela automática conlleva tal consecuencia pues, como claramente indica el último párrafo del apartado primero del artículo 172: "La asunción de la tutela atribuida por la autoridad pública lleva consigo la suspensión de la patria potestad o de la tutela ordinaria", lo que, como puso de manifiesto la propia Ministra de Asuntos Sociales en el acto de defensa del Proyecto en el Congreso de los Diputados ${ }^{42}$, constituye una medida de gran operatividad, pues, hasta su introducción, la Entidad pública tenía muy limitado su cambio de actuación debido a las interferencias de los padres que mantenían la patria potestad.

Cuestión distinta - e incontrovertida- es que la constitución de la tutela $e x$ lege no produce per se la extinción de la patria potestad o tutela, siendo necesario para ello la correspondiente intervención judicial.

Ahora bien, pese al automatismo que debe presidir la actuación administrativa en estos casos, la evidente gravedad de las consecuencias que comporta calificación de una situación como desamparo determina que la calificación deba hacerse restrictivamente [SAP de Valencia 359/2004, de 7 de junio ${ }^{43}$ ] buscando un equilibrio entre el beneficio del menor y la protección de sus relaciones paterno-filiales, de tal manera que sólo se estime la existencia del desamparo cuando se acredite efectivamente el incumplimiento de unos mínimos de atención al menor exigidos por la conciencia social más común, ya que, en definitiva, si primordial y preferente es el interés del menor, huelga subrayar la extraordinaria importancia que revisten los otros derechos e intereses en juego como los de los padres biológicos y los de las restantes personas implicadas.

Por lo demás, no hay duda que la tutela ex lege es una verdadera potestad administrativa en la que concurren todos los requisitos que le son propios. Es, además, una "potestad función" cuanto se ejerce en un interés ajeno al del titular (en este caso, el de los menores) ${ }^{44}$.

42 DSCD núm. 172, de 28 de septiembre de 1995.

${ }^{43}$ Ponente Ilmo. Sr. Enrique de Motta García-España.

${ }^{44}$ En efecto, siguiendo a los Prof. GARCÍA DE ENTERRÍA y FERNÁNDEZ (1993), Curso de Derecho administrativo. Civitas, Madrid, págs. 430 y 431, resulta que en la tutela ex lege concurren todas las notas que son propias de las potestades administrativas, a saber: a) No se genera en relación jurídica alguna, sino que procede directamente del ordenamiento jurídico; b) No recae sobre ningún objeto específico, sino que tiene carácter genérico; c) No consiste en una pretensión particular, sino en la posibilidad abstracta de producir efectos jurídicos, de donde, eventualmente, pueden surgir, como una consecuencia de su ejercicio, relaciones jurídicas; d) No se corresponde con ningún deber, positivo o negativo, sino con una simple sujeción o sometimiento de otros sujetos a soportar los efectos derivados del ejercicio de la potestad. 


\section{EL ACOGIMIENTO RESIDENCIAL}

\subsection{Consideraciones previas}

Tanto la tutela como la guarda implican la separación del menor de las personas con las que convivía y pueden articularse mediante el acogimiento familiar o mediante internamiento en un centro residencial ("institucionalización") Esta última opción es, si se me permite la expresión, "la última de las últimas medidas", ya que sólo procederá cuando no sea posible o recomendable el acogimiento familiar ${ }^{45}$, de manera que, como establece la normativa de menores y reiteradamente señala la jurisprudencia ${ }^{46}$ "asumida por la entidad publica la tutela (...) el acogimiento familiar provisional es una de las modalidades más indicadas de su ejercicio, puesto que evita el ingreso en una institución", sin que con ello quiera decirse que, por excepción, en determinados supuestos (menores cercanos a la mayoría de edad, con trastornos graves de conducta, problemas de salud, o grupos de hermanos numerosos), pueda resultar más beneficioso para el menor su ingreso en un centro residencial ${ }^{47}$.

Sea como fuere, lo cierto es que, a día de hoy, es una realidad que el acogimiento residencial tiene una ratio de aplicación bastante más alta que el aco-

${ }^{45}$ La subsidiariedad del acogimiento residencial frente al familiar está presente en todas las normas sobre esta materia, así vid. Art. 36 de la LMA; el Preámbulo del Decreto 355/2003, de 26 de diciembre (BOJA núm. 245, de 22 de diciembre), que regula el Acogimiento residencial de menores donde se subraya que el internamiento en un centro de protección aparece previsto como una alternativa al acogimiento familiar o su art. 3.2.

El anteproyecto de ley de actualización de la legislación sobre protección a la infancia prevé una modificación del art. 172 del Gc en el que se prevé el acogimiento familiar como regla general y, en particular, en aquellos casos en que se trate de menores de 6 años. Los menores de 3, no ingresarán en centros de protección salvo "imposibilidad debidamente acreditada de adoptar otra medida de protección".

46 SAP de Cantabria 52/2003, de 4 de febrero.

${ }^{47}$ En esta línea, señalan BRAVO, A. y DEL VALLE F. J. (2009): “Crisis y revisión del acogimiento residencial y su papel en la protección infantil”, Papeles del Psicólogo, Vol. 30 (I), pág. 42 que "la función que cumple en la actualidad esta medida protectora difícilmente pudiera ser cubierta por alternativas familiares. Por una lado, debido a la complejidad de las necesidades de estos jóvenes que requieren atención especializada y, por otro, por la dificultad que entrañaría encontrar familias acogedoras que posean un suficiente nivel de capacitación, formación y dedicación para cubrir las necesidades de estos menores". 
gimiento familiar, de manera que el número de niños ingresados en un centro de protección es notablemente superior al de los acogidos en familias ${ }^{48}$.

Llegamos, así, al núcleo central de este trabajo cuyo propósito, como se anticipaba al inicio del mismo, no es otro que esbozar el régimen jurídico administrativo de los centros de protección de menores.

\subsection{Los centros de protección de menores}

Hasta hace muy poco la doctrina había prestado escasa atención a los problemas que planteaba la vertiente administrativa de la guarda administrativa y la tutela ex lege. Con contadas excepciones ${ }^{49}$, la mayor parte de los estudios se habían venido realizando desde una óptica iusprivatista ${ }^{50}$.

El cambio de siglo trae consigo valiosas aportaciones que denuncian la exigua regulación de determinados aspectos ${ }^{51}$, cuya trascendencia resultaba indudable para la lograr una protección efectiva y de calidad de los menores ingresados. Poco se había escrito sobre el procedimiento (administrativo) de de-

${ }^{48}$ De los datos recogidos en el último Boletín Estadístico de Protección a la Infancia, en el año 2006 hubo 10.621 altas en acogimiento residencial y tan sólo 3.399 en acogimientos familiares.

${ }^{49}$ Vid., TOLIVAR ALAS, L. (1991): "Aspectos jurídico-administrativos de la protección de menores", Revista de Administración Pública núm. 124, págs. 35-63.

${ }^{50}$ Centrados, por tanto, en analizar la naturaleza jurídica de este peculiar régimen de protección con el fin de determinar en qué medida le resultarían aplicables las previsiones sobre la tutela ordinaria y -supuesta dicha aplicación- los modos en que debería modularse -en su casopara adaptarla a la diferente realidad que ésta implica. No hay duda, como hace ya años pusiera de manifiesto TOLIVAR ALAS, L. (1991); pág. 35, que "la raíz de la cuestión viene situándose en el campo civil y sus aspectos más frondosos en la concreta rama del Derecho de familia", si bien, como advierte el propio autor "junto a esta perspectiva iusprivatista debemos advertir la función coadyuvante de otros ordenamientos", entre los que cita el penal, el laboral y, como no, el administrativo

${ }^{51}$ Ya a finales de los noventa, VILLA RUBIO, M. (1999): "Protección de menores desamparados", en ESPIAU ESPIAU, S. y VAQUER ALOY, A., (Eds.), Protección de menores, acogimiento y adopción. Marcial Pons, Madrid, pág. 69, constataba esta carencia advirtiendo que "las garantías asistenciales, o de prestación de servicios sociales, tampoco aparecen suficientemente reguladas ni aseguradas, aunque estén garantizadas constitucionalmente como principio rector de la política social y económica".

Entre los trabajos centrados en los aspectos administrativos del problema pueden citarse el de DE PALMA DEL TESO, A (2006): Administraciones públicas y protección de la infancia. INAP, Madrid, y más recientemente el ya citado de SÁINZ CANTERO, Ma B. y PARDO MARTÍNEZ, E. (2010). 
claración de desamparo, y menos (o nada) aparecía previsto en relación con el régimen jurídico de los centros de protección.

La escasez de aportaciones puede achacarse a la precariedad normativa: ninguna regulación de detalle sobre estos centros se contiene la normativa estatal ${ }^{52}$ y la actuación del legislador regional -competente en la materia- se produce con un sorprendente - $\mathrm{e}$ injustificado- retras ${ }^{53}$, de manera que las primeras normas en las que se regulan los distintos aspectos relacionados con el régimen jurídico administrativo de estos centros se publican a retortero de las denuncias sobre los desajustes de la regulación existente que se percibe como desfasada y palmariamente insuficiente ${ }^{54}$ para hacer frente a las nuevas necesidades sociales ${ }^{55}$.

En la Comunidad Autónoma Andaluza, la estructura normativa se ha ido construyendo poco a poco, a partir de la LOPM, dando lugar a una intrincada red de disposiciones ${ }^{56}$.

En primer lugar, encontramos la Ley Orgánica 1/1996, de 15 de enero, de Protección Jurídica del Menor ${ }^{57}$, la Ley 2/1988, de 4 de Abril, de Servicios

${ }^{52}$ La Exposición de Motivos del Anteproyecto de la Ley Orgánica complementaria al Anteproyecto de Ley de actualización de la legislación sobre protección a la infancia, denuncia, en particular, el déficit normativo existente en relación con los centros de menores con dificultades e adaptación o trastornos de conducta.

${ }^{53}$ Idéntica demora denuncia en la normativa reguladora de los centros residenciales para personas mayores FERNÁNDEZ RAMOS, S. (2007): en su excelente trabajo "Los centros residenciales para personas mayores, especial referencia a Andalucía", Revista Andaluza de Administración Pública núm. 67, pág. 21 y ss.

${ }^{54}$ En 1999, el Informe Especial del Defensor del Pueblo Andaluz al Parlamento sobre el Sistema de Protección de Menores (Tomo I), destacaba la importancia de acometer el desarrollo reglamentario de la LMA, desarrollo del que dependía su efectividad habida cuenta "la dificultad de aplicación directa del texto legal". Este informe está disponible a texto completo en la página del Defensor del Pueblo Andaluz, apartado "Informes especiales": http://www.defensorand.es/informes_y_publicaciones/informes_estudios_y_resoluciones/informes_especiales/informe_0000/proteccion_menores/index.html.

${ }^{55} \mathrm{El}$ número de menores tutelados por entes públicos ha aumentado considerablemente durante los últimos años por diversos factores entre los que pueden citarse: la crisis económica; el incremento del número menores extranjeros no acompañados que llegan a nuestro país o el progresivo aumento de las familias desestructuradas.

${ }^{56}$ Se ha destacado que, si bien se trata de "un marco administrativo lleno de buena técnica y de excelentes intenciones", falla a causa de una inadecuada ordenación de los medios personales, materiales, de tiempo y de procedimiento. OGAÑA RODRÍGUEZ, A. (2005), pág. 3.

57 Vid. Art. 21 
Sociales de Andalucía y la Ley 1/1998, de 20 de abril, del Menor de Andalucía (LMA) ${ }^{58}$, disposiciones en las que se recogen las líneas maestras del sistema de la regulación de los centros de protección.

En segundo lugar, se sitúan diversas normas reglamentarias que se insertan, bien en el genérico marco del sistema de servicios sociales (p. ej. el Decreto $87 / 1996$, de 20 de febrero ${ }^{59}$, que regula la autorización, registro y acreditación de los servicios sociales de Andalucía), bien en el contexto específico de la protección de menores (tal es el caso del Decreto 355/2003, de 16 de diciembre, sobre Acogimiento Residencial de Menores o el Decreto 42/2002, de 12 de febrero, sobre régimen de desamparo, tutela y guarda administrativa). En estas normas se contienen algunas referencias concretas sobre la medida de alojamiento residencial y a las características de los centros.

Asimismo, deben tenerse en cuenta una serie de Órdenes - muchas de ellas de reciente publicación- en las que se contiene una regulación pormenorizada de los centros. Entre ellas, destacan la de 9 de noviembre de $2005^{60}$, que regula la cooperación entre la Consejería para la Igualdad y Bienestar social y las entidades colaboradoras en el acogimiento residencial en Centros de Protección de Menores y la de 23 de octubre de 2007 que aprueba el Reglamento marco para organización y funcionamiento de los mismos ${ }^{61}$.

Por último, culminan el sistema los Reglamentos de Organización y funcionamiento de que deben dotarse (aunque no siempre lo hagan) cada uno de los centros en los que se reflejen los derechos de los menores, las normas de convivencia y los criterios para el ejercicio de la potestad de corrección ${ }^{62}$.

58 Vid. arts. 36 y ss.

59 Modificado por Decreto 102/2000, de 15 de marzo.

${ }^{60}$ BOJA núm. 222, de 14 de noviembre.

61 BOJA núm. 223, de 13 de noviembre.

62 Conforme a lo dispuesto en el art. 52 del Decreto 325/2003 "Una vez aprobado el Proyecto Educativo de Centro, la dirección y los profesionales de los equipos educativos y técnico deberán definir el Reglamento de Organización y Funcionamiento del Centro. Dicho Reglamento deberá concretar los instrumentos y procedimientos materiales, personales y relacionales de la intervención con los menores acogidos en el centro, en función a los elementos básicos recogidos en el presente Decreto.

Los Reglamentos de Organización y Funcionamiento de los Centros deberán ajustarse a los principios, criterios y directrices establecidos en el Reglamento Marco que a tal fin elaborará la Dirección General competente en materia de protección de menores, de acuerdo con el presente Decreto. 
El análisis del régimen jurídico administrativo de los centros de protección debe hacerse, por tanto, partiendo del esquema general antes expuesto, del que resultan diversas previsiones sobre los requisitos que éstos deben reunir.

\subsubsection{Concepto, clases y requisitos}

\subsubsection{Concepto}

Los Centros de protección ${ }^{63}$ pueden definirse como los espacios convivenciales destinados a la guarda y educación de los menores sobre los que se haya adoptado alguna de las medidas contempladas en el artículo 172 del Código Civil. Como señala la Orden de 28 de julio de $2000^{64}$, éstos deben asumir la responsabilidad sobre el desarrollo integral del menor, garantizándole la adecuada satisfacción de sus necesidades biológicas, afectivas y sociales en un ambiente de seguridad y protección, potenciando experiencias de aprendizaje y el acceso a los recursos sociales en las mismas condiciones que cualquier otra persona de su edad.

Como puede apreciarse, la noción de "centro de protección" ha experimentado una importante evolución, de manera que, lejos de las frías "casas de

Una vez elaborado el Reglamento de Organización y Funcionamiento del Centro será tramitado para su informe al Servicio especializado de protección de menores, que a su vez lo remitirá a la Dirección General competente en materia de protección de menores para su aprobación, debiendo adecuarse al Reglamento Marco y a las disposiciones legales vigentes.

Una vez aprobado el Reglamento de Organización y Funcionamiento de Centro será revisado cada cinco años con el fin de evaluar su validez. No obstante, a iniciativa del servicio especializado de protección de menores o a petición del Centro mediando razones justificadas y una vez pasados dos años desde su aprobación, podrá interesarse su revisión”.

63 Vid. el artículo 17 del Decreto 355/2003, de 16 de diciembre y la Orden de 23 de octubre de 2007, que aprueba el Reglamento marco para la organización y funcionamiento de los centros de protección de menores en el ámbito de la Comunidad Autónoma de Andalucía.

Entre las escasísimas definiciones doctrinales sobre el concepto de centros de protección puede destacarse la propuesta por SÁINZ-CANTERO CAPARRÓS, M ${ }^{\mathrm{a}}$ B. y PARDO MARTÍNEZ, E. (2010), pág. 65, que los configuran como "recursos residenciales alternativos a la intervención en un entorno familiar y de carácter predominantemente educativo, organizados para favorecer las condiciones normalizadas de vida de los menores cuya tutela o guarda ha sido asumida por la Administración competente en materia de protección de menores".

64 Vid. Anexo I (punto 2.5.2) de la Orden de 28 de julio de 2000, que regula los requisitos materiales y funcionales de los Servicios y Centros de Servicios Sociales de Andalucía y aprueba el modelo de solicitud de las autorizaciones administrativas. 
expósitos", se pretende que éstos reproduzcan el modelo de convivencia familiar, garantizando la atención integral al menor, no limitada, por tanto, a aspectos físicos (alimentación, o salud) sino comprensiva de otros como la cultura y ocio $^{65}$. Tal cambio de orientación se plasma claramente en el texto del Preámbulo de la Orden de 9 de noviembre de $2005^{66}$, en el que puede leerse que los centros de protección "han pasado a ser pequeñas unidades convivenciales, en las que seis u ocho menores reciben atención por equipos de cuatro o cinco educadores (...) así como personal técnico, que intentan reproducir patrones de relación basados en los que hoy nuestra sociedad considera como modelos de familias, tanto en la atención prestada en el propio centro como en el esfuerzo de normalización e integración familiar que se realiza con cada menor" $" 67$.

El ingreso del menor debe hacerse en el centro que resulte más adecuado a sus necesidades y por el tiempo que resulte imprescindible ${ }^{68}$, de manera que como señaló la Presidenta de la Asociación estatal de acogimiento familiar (ASEAF) en su comparecencia ante la Comisión Especial del Senado para el

${ }^{65}$ El punto 2.4.1 del Anexo I de la Orden de 28 de julio de 2000 (BOJA núm. 102, de 5 de septiembre), que regula los requisitos materiales y funcionales de los Servicios y Centros de Servicios Sociales de Andalucía y aprueba el modelo de solicitud de autorizaciones administrativas, prevé - dentro de los requisitos funcionales específicos de los centros de protección- que en éstos se garantizará "por medios propios o ajenos, la atención integral a los menores en el conjunto de sus necesidades básicas de alimentación, salud (en todos sus aspectos), educación, así como las de ocio y cultura, durante las veinticuatro horas de todos los días del año, sin que la prestación del servicio pueda repercutir negativamente el periodo vacacional del personal del Centro.

${ }^{66}$ Esta Orden regula la cooperación entre la Consejería y las entidades colaboradoras en el acogimiento residencial en Centros de Protección de Menores.

${ }^{67}$ Por provincias, Sevilla alberga un total de 54 centros de protección, seguida de Granada, con 48; Cádiz, con 41; Málaga, con 35; Almería, con 31; Huelva, con 27; y Córdoba y Jaén, con 20. En cuanto a los menores acogidos, la mayoría se encuentran en Sevilla, donde se presta atención a 483 menores desamparados; seguida de Cádiz, donde se acoge a 465 menores; Málaga, con 430 menores; Granada, con 363; Huelva, con 339; Almería, con 295; Jaén, con 223 y Córdoba, con 160 (datos disponibles en la URL: http://www.diariocritico.com/2010/Diciembre/noticias/244934/menores-junta.html)

${ }^{68}$ La provisionalidad del internamiento se subraya en diversas disposiciones. Así, el art. 8 del Decreto 42/2002, de 12 de febrero prevé que "Los menores sujetos a medidas de protección tienen derecho a no estar institucionalizados más que el tiempo estrictamente necesario para la aplicación de una medida alternativa. En todo caso, el ingreso en un centro residencial, o la integración en una familia acogedora, deberá ser cuidadosamente planificada, dando apoyo a los menores para las fases de preparación al ingreso, acoplamiento y adaptación a la nueva situación". 
estudio de la problemática de la adopción nacional y otros temas afines ${ }^{69}$, deberían establecerse límites temporales razonables en los que se lleven a cabo los trabajos de retorno del menor a su familia o la búsqueda de otras alternativas, evitando que los menores permanezcan en estos centros la mayor parte de su vida ocupando plazas de forma permanente y saturando las instituciones. Además, como apostilla el Defensor del Pueblo ${ }^{70}$, el ingreso de un menor en uno de estos centros es compatible -en su caso, y siempre que convenga a su interés- con el mantenimiento de relaciones personales y con la estancia en su propia familia o con familias colaboradoras los fines de semana o periodos vacacionales.

\subsubsection{Clases}

La tipología de los centros de menores trasluce el deseo de que su estructura y funcionamiento reproduzca, en la medida de lo posible, la de una familia, de manera que el menor pueda recibir una atención personalizada.

El art. 19 del Decreto 355/2003 clasifica los centros de protección en casas y residencias. Las primeras se configuran como núcleos de convivencia ubicados en viviendas normalizadas (pisos o viviendas unifamiliares independientes, adosadas o pareadas $)^{71}$ que siguen los patrones de unidades familiares. Por su parte, bajo el nombre de residencias se incluyen los centros que agrupan varios núcleos de convivencia similares a las casas y en los que los menores acogidos comparten habitualmente los espacios comunes". La previsión de que dichos centros se sigan "los patrones de unidades familiares" se refiere a la necesidad de que el número de menores acogidos sea lo más reducido posible, facilitando, de este modo, un más estrecho contacto con ellos y creando, al mismo tiempo, un entorno de convivencia más cálido, cercano y acogedor ${ }^{72}$.

A su vez, en función de su titularidad los centros pueden ser públicos (o "propios") y privados (colaboradores) ${ }^{73}$. Dentro de los primeros pueden incluirse, además de aquellos cuya titularidad y gestión corresponde a la Administra-

${ }^{69}$ BOCG-Senado de 17 de noviembre de 2010, pág. 14.

${ }^{70}$ Defensor del Pueblo (2009), pág. 83.

${ }^{71}$ Art. 2.5.2.2 de la Orden de 28 de julio de 2000.

${ }^{72}$ La Orden de 28 de julio de 2000 afina aún más al precisar que las residencias tendrán capacidad para acoger entre 9 y 35 menores, procurando que su distribución se asemeje a una vivienda familiar. Por su parte, respecto de las casas, podrá tratarse tanto de "pisos como de viviendas unifamiliares independientes, adosadas o pareadas". 
ción, los que son gestionados por entidades con personalidad jurídico-privada dependientes de ésta (caso de las Fundaciones) o por gestores privados. Por su parte, los centros privados son aquéllos cuya titularidad corresponde a una entidad colaboradora, entendiéndose por tales aquellas instituciones privadas $\sin$ ánimo de lucro que estén habilitadas para ejercer las funciones de guarda y atención residencial de los menores desamparados, y que hayan suscrito el correspondiente documento de colaboración con la Administración. Estos últimos son, como regla general, mucho más numerosos. Así, por ejemplo, Andalucía cuenta con un total de 276 centros de protección de menores de los cuales, tan sólo 20 son propios, siendo los restantes 256 centros colaboradores ${ }^{74}$. Unos y otros integran la red pública de centros de protección de menores ${ }^{75}$.

Para el desempeño de sus funciones, los centros colaboradores reciben la correspondiente subvención de la Administración, siendo, precisamente, la insuficiencia de recursos económicos el mayor problema que se viene denunciando para el logro de una eficaz protección de los menores, suponiendo un grave obstáculo para su actuación ${ }^{76}$. En cualquier caso, siempre que la Administración haya delegado la gestión de los centros en entidades privadas debe exigirse las mismas una total transparencia en la gestión de los gastos, como requisito indispensable para que su actuación se adecúe a los principios de eficacia y eficiencia recogidos en la Constitución ${ }^{77}$, impidiendo que su actividad se realice con fines lucrativos.

${ }^{73}$ La posibilidad de entidades colaboradoras de la Administración en la protección de menores se reconoce en la Disposición adicional $1^{a}$ de la Ley 21/1987, de 11 de noviembre.

${ }^{74}$ Datos recogidos en el Informe Anual 2009 del Defensor del Menor de Andalucía (apartado 11)

${ }^{75}$ La idea de sistema como reflejo del compromiso público con la asistencia social, se pone de manifiesto por VILLAR ROJAS, F. J. (2005): "Formas de gestión de los servicios sociales. En particular, la vinculación de gestores privados al sistema público mediante conciertos y convenios", Documentación Administrativa núm. 271-272, pág.391.

${ }^{76}$ No es éste un problema de fácil solución si se tiene en cuenta la nada despreciable cantidad que supone el mantenimiento de cada niño ingresado. De conformidad con lo dispuesto en el Anexo IV de la Orden de 9 de noviembre de 2005, que regula la cooperación entre la Consejería y las entidades colaboradoras en el acogimiento residencial en Centros de Protección de Menores, el coste diario por cada menor ingresado puede llegar a alcanzar los 120 euros en el caso de que se trate de niños con trastornos de conducta., de manera que el coste mensual de cada niño ingresado superaría los 3.500 euros, lo que es otro argumento a favor del acogimiento familiar que resulta mucho más económico.

77 DEFENSOR DEL PUEBLO (2009), pág. 415. 
Finalmente, con independencia de su tipología, una última clasificación puede hacerse en función del programa que desarrollen, distinguiéndose entre los centros de primera acogida (o acogida inmediata ${ }^{78}$ ) los que desarrollan programas de atención residencial básica ${ }^{79}$-que son los más numerosos- y, por último, los que desarrollan programas específicos con menores que presentan necesidades especiales o tienen dificultades de adaptación en su comportamiento y que, por sus características, necesitan una atención especializada en función del tratamiento que precisen (menores en con trastornos de conducta, extranje$\operatorname{ros}^{80}$, menores con problemas de adicción, en situación de dificultad social...).

No se trata de categorías excluyentes, ya que es posible que un mismo centro desarrolle más de un programa ${ }^{81}$. En tal caso, éstos deberán ser compatibles entre sí y no afectar al normal desarrollo de la atención a los perfiles y problemática de los menores atendidos debiendo ubicárseles en unidades funcionales o módulos convivenciales independientes. Ahora bien, esta previsión, si bien ideal, es frecuentemente incumplida en la práctica, hasta el punto que no sólo se mezclan menores que deberían estar separados en función del programa de protección, sino, lo que es más, grave, a menudo se ingresa en centros de protección a menores que, por haber cometido algún ilícito de los contemplados en la LO 5/2000, de 12 de enero, de Responsabilidad penal de los menores, deberían de ingresar en un centro de reforma y no en un centro de protección ${ }^{82}$.

\footnotetext{
${ }^{78}$ Son aquellos en los que se atiende, con carácter de urgencia y en horario ininterrumpido a los menores que se encuentren en grave situación de desprotección o en alto riesgo físico o psíquico, teniendo como objetivo el estudio y diagnóstico del menor y su entorno socio-familiar, en aras a determinar la medida y recurso de protección más adecuados así como el plan a seguir con su menor y su familia.

El ingreso en estos centros es siempre temporal, en tanto se sustancie el procedimiento que determine la medida a adoptar.

${ }^{79}$ En estos centros se ofrece al menor el alojamiento, la convivencia y la educación que precisa para su desarrollo integral por el periodo necesario hasta que pueda producirse el retorno a su familia si fuera posible, la preparación para la emancipación o vida autónoma cuando cumplan dieciocho años o se adopte otra medida alternativa

${ }^{80}$ En relación con la tutela de los menores extranjeros vid. FERNÁNDEZ MASÍA, E. (2001): "Las entidades públicas y la protección de los menores extranjeros en España" (Ref. La Ley 1642/2001).

${ }^{81}$ Así lo prevé la Orden de 9 de noviembre de 2005 (BOJA núm. 222, de 14 de noviembre), que regula la cooperación entre la Consejería y las entidades colaboradoras en el acogimiento residencial de los Centros de Protección de Menores.

${ }^{82}$ La necesidad de diferenciar claramente los distintos supuestos de institucionalización se subraya en el Informe de la Comisión Especial del Senado para el Estudio de la problemática de la adopción internacional y otros temas afines (2010), pág. 52.
} 
En función del programa específico que desarrollen, se contempla que algunos centros puedan adoptar medidas de restricción de libertad de los menores, a este respecto debe indicarse que, aún cuando dichas medias pueden estar justificadas en algunos casos, lo que de ninguna manera es de recibo es que no se regulen de forma explícita las garantías y procedimientos que deben seguirse para su adopción ${ }^{83}$. Ello nos conduce directamente a la importancia del Reglamento de Organización y Funcionamiento como instrumento esencial de que deben dotarse los centros y en el que deben de especificarse algunos aspectos esenciales de la vida diaria de los menores ingresados (régimen de visitas, salidas al exterior, conductas prohibidas, posibles sanciones, etc. ) que, de otro modo, quedarían confiadas a la discrecionalidad del centro, provocando una inadmisible inseguridad para los menores, así como la imposibilidad de control jurisdiccional de su actividad.

Debe tenerse en cuenta que los centros no gozan de plena libertad para definir el contenido de los Reglamentos de Organización, ya que éstos deberán ajustarse, en todo caso, a los principios, criterios y directrices recogidos el Reglamento Marco, así como a las demás disposiciones legales vigentes. En relación con el Reglamento Marco, aunque con notable retraso, ha sido definitivamente aprobado en Andalucía en el año 2007 ${ }^{84}$, debiendo todos los Centros que dispusiesen de Reglamentos de Organización adoptados con anterioridad ajustar su con tenido a lo dispuesto en él.

Una vez aprobado, el Reglamento de Organización será revisado cada cinco años con el fin de evaluar su validez, si bien, a iniciativa del servicio especializado de protección de menores o a petición del Centro, mediando razones justificadas y una vez pasados dos años desde su aprobación, podrá interesarse su revisión.

${ }^{83}$ En su Informe, el Defensor del Pueblo denuncia que en algunas Comunidades autónomas no contemplan ninguna garantía especial para la adopción de tales medidas. Vid. Defensor del Pueblo (2009), pág. 90.

${ }^{84}$ En Andalucía, desde el año 2003, todos los centros de protección deben aprobar dicho Reglamento de Organización. Así lo prevé el artículo 22 del Decreto 355/2003, de 16 de diciembre (BOJA núm. 245, de 22 de diciembre). Conforme al artículo 52 de este Decreto, dicho Reglamento deberá concretar los instrumentos y procedimientos materiales, personales y relacionales de la intervención con los menores acogidos, ajustándose a los principios y criterios y directrices establecidos en el Reglamento Marco, cuya elaboración se encomienda a la Dirección General de protección a la infancia. El Reglamento Marco fue definitivamente a probado por Orden de la Consejería de 23 de octubre de 2007 (BOJA núm. 223, de 13 noviembre). 


\subsubsection{Requisitos}

Para el adecuado desempeño de las funciones que se les encomiendan los centros de menores deben de reunir una serie de condiciones materiales y funcionales. Para conocer cuales sean, debe estarse a lo dispuesto en el Decreto $355 / 2003$, cuyo art. 20, remite, a su vez, a lo previsto en la normativa general sobre servicios sociales. Ello nos conduce al Decreto 87/1996, de 20 de febrero y a la Orden de 28 de julio de $2000^{85}$. El Anexo I de esta última contiene una minuciosa regulación de los requisitos exigibles, en general, a todos los Centros de Servicios Sociales ${ }^{86}$ y, en particular, de los requeridos para cada uno de ellos (entre los que se encuentran los de protección de menores). Naturalmente, tales requisitos deben concurrir tanto en todos los centros públicos como en los colaboradores.

\section{A. Materiales}

Los centros de menores deben de reunir, además de los requisitos generales previstos para los Centros y Servicios sociales, otros específicos en función del tipo de programa que desempeñen. Los requisitos materiales generales se refieren a aspectos físicos (ubicación ${ }^{87}$ y emplazamiento) urbanísticos, arquitectónicos (altura, accesos, supresión de barreras arquitectónicas, materiales, acabados, iluminación, ventilación...), de instalaciones (agua corriente, electricidad, gas, climatización), equipamiento, protección, seguridad, etc. Asimismo, dentro de los requisitos materiales generales se recoge la necesaria división del centro por zonas (de administración, de servicios generales, de atención especializada y residencial), con previsiones muy detalladas sobre las características de los dormitorios, aseos o comedor.

Los requisitos materiales específicos aparecen previstos para los centros que desarrollan programas especiales (como es lógico su infraestructura debe ser la idónea para que en ellos pueda desarrollarse el programa correspon-

85 BOJA núm. 102, de 5 de septiembre.

${ }^{86}$ Dentro de los requisitos materiales generales se incluyen los relativos a las condiciones físicas y dotacionales (requerimientos físicos, urbanísticos, arquitectónicos, de instalaciones -agua caliente, instalaciones eléctrica y de gas, climatización...- equipamiento, protección y seguridad, etc); así como a la distribución de las zonas (de administración, de servicios generales, residencial..).

87 Como ha señalado el Defensor del Pueblo (2009), pág. 83, deberá procurarse la ubicación del centro en la comunidad a fin de favorecer la integración social de los menores ingresados en el mismo. 
diente) o los destinados a la acogida inmediata. La apreciación la concurrencia de tales requisitos no plantea problema alguno ya que - a diferencia de lo que ocurre con los funcionales- su existencia puede constatarse mediante la oportuna inspección ${ }^{88}$.

\section{B. Funcionales}

Como los materiales, los requisitos funcionales que deben reunir los centros de protección se clasifican en generales (comunes a los demás servicios y centros) y particulares. Dentro de los primeros se incluyen, junto algunas exigencias obvias (como que el centro esté adaptado as las condiciones de sus usuarios así como a los programas que desarrollen) otras relativas a la obligatoriedad de que los centros dispongan de un registro de usuarios (donde consten sus datos así como la fecha de ingreso y de baja) así como de un reglamento de régimen interior y de Hojas de Reclamaciones ${ }^{89}$. Asimismo, dentro de este apartado se incluyen otros aspectos como el relativo a los recursos humanos (Director, y demás personal del centro), menús, medidas higiénico-sanitarias, o mantenimiento.

Los requisitos funcionales específicos giran en torno a las condiciones de ingreso y atención ofrecida a los menores ingresados, la obligación de que el centro cuente con un Proyecto Educativo y un expediente personal que debe abrirse a cada menor, así como el número y cualificación del personal del centro.

${ }^{88} \mathrm{Tal}$ y como se recoge en el Protocolo de Inspecciones a los Centros de Protección de la Fiscalía General del Estado, el epígrafe 3.-4 12) de la Instrucción 3/2008, de 30 de julio sobre el Fiscal de Sala Coordinador de Menores y las Secciones de Menores, uno de los cometidos de la Sección de Menores en materia de protección es el de visitar periódicamente los Centros de Protección de Menores (art. 21.4 LOPJM), inspeccionando las instalaciones, las medidas de seguridad e higiene, entrevistándose reservadamente con los menores que así lo soliciten y promoviendo la corrección de las deficiencias que se observen (el Protocolo está disponible a texto completo en la siguiente dirección:

http: $/ /$ www.fiscal.es $/ \mathrm{cs} /$ Satellite?buscador $=0 \& \mathrm{c}=$ Page\&cid $=1240559967773 \&$ codigo $=\mathrm{FG}$ $\underline{\mathrm{E}}$ \&language $=$ es\&newPagina $=7$ \&pagename $=$ PFiscal $\% 2$ FPage $\% 2$ FFGE buscadorDocEspecialista\&rendermode $=98 \mathrm{~s}$.

${ }^{89} \mathrm{El}$ artículo 16 del Decreto 355/2003, de 16 de diciembre, recoge el derecho de los menores acogidos en Centros de protección y de sus familiares a "expresar su disconformidad acerca de cualquier aspecto de la atención residencial, incluido el trato recibido del personal, así como a recibir una contestación expresa al caso planteado", para lo que podrán solicitar en cualquier momento las hojas de reclamaciones o el libro de sugerencias, sin perjuicio de que puedan plantear directamente sus quejas al Defensor del Menor o al Ministerio Fiscal. 
El desarrollo de alguna de estas previsiones generales se contiene en el Decreto $355 / 2003^{90}$. En él se regulan los instrumentos para la acción educativa que se clasifican en generales (Proyecto y Curriculum ${ }^{91}$ Educativos del Centro; Reglamento de Organización y Funcionamiento; Programación y Memoria Anual) e individuales (Informes Propuesta, de Observación Inicial y de Seguimiento Educativo y Proyecto Educativo Individualizado). Respecto de la organización del personal, se prevé la siguiente estructura organizativa: Dirección, Subdirección (que será facultativa), equipo educativo, equipo técnico y personal de administración y servicios. El perfil, funciones y responsabilidades de cada uno de ellos se concretarán en el Reglamento de Organización de cada uno de los centros de acuerdo con las directrices contenidas en el Reglamento Marco ${ }^{92}$.

Resulta imposible realizar un análisis en detalle de la problemática que se plantea en relación con cada uno de los requisitos mencionados, por ello, en las páginas que siguen se va a prestar particular atención entre ellos a la "habilitación" y al convenio de colaboración. Ahora bien, antes se hará referencia a otros requisitos que condicionan la posibilidad de solicitar y celebrar una y otro.

\section{Requisitos previos: la autorización y la inscripción.}

Para poder ser habilitada y celebrar el convenio de colaboración, la entidad debe obtener la correspondiente autorización administrativa de funcionamiento $^{93}$. El art. 4 de la Orden de 2 de noviembre de 2005 se remite en este punto a lo establecido en el Decreto 87/1996, de 20 de febrero que resulta, pues, plenamente aplicable. Conforme a lo establecido en el art. 5 de dicho Decreto, la autorización administrativa es precisa también para creación, construcción, y modificación sustancial, estructural o funcional, del Centro o Servicio. En cambio, para cambio de titularidad, cese del Servicio o cierre del Centro bastará con la comunicación previa.

\footnotetext{
90 Arts. 49 y siguientes.

${ }^{91}$ Vid. la Orden de 23 de julio de 2007 (BOJA n ${ }^{\circ}$ 159, de 13 de agosto), que Aprueba el Currículum Educativo Marco para los Centros de Protección de Menores, en el ámbito de la Comunidad Autónoma de Andalucía.

92 Vid. apartado 8 de la Orden de 23 de octubre de 2007, que aprueba el Reglamento marco para la organización y funcionamiento de los centros de protección.

${ }^{93} \mathrm{El}$ art. 4 de la Orden de 2 de noviembre de 2005 se remite en este punto a lo establecido en el Decreto 87/1996, de 20 de febrero que resulta, pues, plenamente aplicable. Conforme a lo establecido en el art. 5 de dicho Decreto es precisa también autorización administrativa para creación, construcción, y modificación sustancial, bien estructural o funcional, del Centro o Servicio. En cambio, para cambio de titularidad, cese del Servicio o cierre del Centro bastará con la comunicación previa.
} 
El otorgamiento de la autorización de funcionamiento se condiciona a una autorización previa-cuyo fin es comprobar la adecuación del proyecto presentado a las condiciones mínimas materiales, así como su idoneidad para satisfacer las necesidades que justifican su creación ${ }^{94}-$ y a la obtención de las correspondientes licencias municipales.

Finalmente, no podrá celebrarse el convenio sin que la entidad se haya inscrito en el Registro de de Entidades, Servicios y Centros ${ }^{95}$. Dicha inscripción que no tiene carácter constitutivo- es indispensable para la obtención de cualquier clase de ayuda o subvención, determinando su falta -como es obvio- la clandestinidad del centro y a la consiguiente responsabilidad administrativa.

\section{La habilitación y el convenio de colaboración.}

\section{a) La habilitación}

Como se ha dicho, las funciones de protección de menores no es exclusiva de los entes públicos sino que, en ciertos aspectos, la colaboración privada no sólo es factible sino deseable. La intervención de sujetos privados se justifica en la supuesta mayor celeridad de su actuación frente a la tradicional lentitud administrativa y en la constatación del valioso papel que, tradicionalmente, han jugado determinadas instituciones (religiosas o no) en la protección de menores ${ }^{96}$.

Ahora bien, para que entidades privadas actúen como colaboradoras es necesario que previamente hayan sido habilitadas por la Comunidad Autónoma correspondiente. La necesidad de habilitación ya se recogía en la Disposición adicional $1^{a}$ de la Ley 21/1987, de 11 de noviembre, a cuyo tenor: "Las Comunidades Autónomas, en virtud de su competencia en materia de protección

${ }^{94}$ Art. 10.1 del Decreto 87/1996, de 20 de febrero.

${ }^{95}$ Vid. Art. 18 y ss. del Decreto 87/1996, de 20 de febrero.

${ }^{96}$ Como señala REBOLledo VARELA, A. L. (1993): Comentario a la Disposición adicional $1^{\text {a }}$ de la Ley 21/1987, de 11 de noviembre, en BERGOVITZ RODRÍGUEZ-CANO, R. (Coord.), Comentarios a las reformas del Código Civil. Tecnos, Madrid, pág. 356, "la admisión de las llamadas Instituciones Colaboradoras de Integración Familiar dentro de los procedimientos de adopción y acogimiento supone por parte del legislador una toma de posición que, en cierta medida, no sólo constituye una novedad a nivel legal, sino también una decisión que (...) no cabe duda que no encaja con comodidad en la filosofia de la Ley (exclusión de la iniciativa y participación de particulares y entidades privadas en las adopciones y acogimientos) y de ahí que el propio legislador, aún admitiéndolas, las trate con un cierto recelo”. 
de menores, podrán habilitar en su territorio, como instituciones colaboradoras de integración familiar, a aquellas Asociaciones o Fundaciones no lucrativas, constituidas conforme a las leyes que le sean aplicables, en cuyos estatutos o reglas figure como fin la protección de menores y siempre que dispongan de los medios materiales y equipos pluridisciplinares necesarios para el desarrollo de las funciones encomendadas".

De este modo, la habilitación persigue una doble finalidad ${ }^{97}$ : por una parte, establece un control administrativo previo que garantiza que la entidad reúne las condiciones que le van a permitir el adecuado cumplimiento de sus funciones y, por otra, se evita la proliferación indiscriminada de instituciones de este tipo. Puede entenderse, por tanto, que en relación con los centros de menores, la habilitación juega el mismo papel que la acreditación prevista en el Decreto 87/1996, de 20 de febrero, respecto de de los Centros de Servicios Sociales en Andalucía ${ }^{98}$. En cualquier caso, su concesión no es obligatoria, ya que, como prevé la Disposición adicional citada, las Comunidades autónomas podrán habilitar a determinadas Asociaciones o Fundaciones, sin que deban hacerlo necesariamente.

Los requisitos a los que se condiciona la habilitación se explicitan, por lo que a Andalucía se refiere, en el artículo 3 de la Orden de 9 de noviembre de $2005^{99}$. Son los siguientes: a) Estar legalmente constituidas; b) Carecer de ánimo de lucro; c) Figurar entre sus fines estatutarios la protección de menores; d) Tener su ámbito de actuación en la Comunidad Autónoma de Andalucía; e) Estar inscritas en el Registro de Entidades de la Consejería; f) Comprometerse a atender a los menores en función del número de plazas autorizadas y convenidas con la Consejería; y, por último, g) Disponer de la organización e infraestructura adecuadas para el desarrollo de las funciones protectoras así como disponer de las condiciones y medios humanos y materiales necesarios para cumplir las exigencias derivadas de la Orden desde el momento de la vigencia del convenio que se suscriba.

97 Vid. REBOLLEDO VARELA, A. L. (1993), págs. 350-366.

98 Como señala el art. 25 de dicho Decreto la acreditación es el acto por el que la Administración garantiza que los Servicios y Centros de Servicios Sociales a quienes se otorga reúne los mínimos de calidad exigidos reglamentariamente.

99 BOJA núm. 222, de 14 de noviembre. Esta Orden regula la cooperación entre la Consejería y las entidades colaboradoras en el acogimiento residencial en Centros de Protección de Menores. 
Ninguna duda plantea la exigencia de que se trate de entidades legalmente constituidas ${ }^{100}$. Sin embargo, sí surgen algunos problemas respecto de alguno de los restantes requisitos mencionados. Así, ocurre, por ejemplo, con la exigencia de que entre sus fines "figure la protección de menores", en cuanto podría suscitar la duda de si cabe que, además de esta finalidad tales entidades, tengan alguna otra, pues del texto citado no parece colegirse la exigencia que aquella deba ser su finalidad exclusiva.

Cuestión distinta es si el otorgamiento de la habilitación es un acto reglado de manera que, reunidos los requisitos necesarios, deba concederse necesariamente, o si, por el contrario, la Administración goza de un margen de apreciación discrecional. En mi opinión, si bien puede sostenerse el carácter reglado de dicho acto $^{101}$, ello no significa que la habilitación permita a la entidad, inmediatamente, sin más requisitos, llevar a cabo funciones en materia de protección de menores ya que, para que ello sea posible, deberá haber suscrito el correspondiente convenio de colaboración ${ }^{102}$, convenio que, entiendo, es de suscripción discrecional y de existencia determinante para el desempeño de aquéllas funciones.

Por otra parte, a la vista del contenido de la citada Disposición Adicional, se ha entendido que las únicas entidades que podían habilitarse como colaboradoras eran las asociaciones o fundaciones no lucrativas, con exclusión, por tanto, de cualquier otra institución. A mi juicio, esta afirmación debe matizarse, de manera que las Comunidades Autónomas que tengan asumida y transferida la competencia en materia de protección de menores podrán prever la habilitación de otras entidades, ampliando, por tanto, el elenco de las mencio-

${ }^{100}$ La referencia a la legislación aplicable debe entenderse hecha en Andalucía a la Ley 10/2005, de 31 de mayo, de Fundaciones (los requisitos para la constitución de las fundaciones se regulan en los artículos 8 a 14). En cuanto a las asociaciones, su constitución e inscripción se rige por lo dispuesto en la Ley orgánica 1/2002, de 22 de marzo, reguladora del Derecho de Asociación y la Ley 4/2006, de 23 de junio (BOJA núm. 126, de 3 de julio) de Asociaciones de Andalucía.

${ }^{101}$ Esta es también la opinión de REBOLLEDO VARELA, A. L. (1993), pág. 358.

${ }^{102}$ La suscripción del convenio de colaboración puede no considerarse oportuna por diversas causas entre las que pueden citarse que el número de centros se considere suficiente o que no se dispongan de los recursos presupuestarios necesarios. En todo caso, la suscripción del mismo requerirá preceptivamente el informe favorable de la Dirección General de de Infancia y Familias. Para que el informe sea favorable deberán concurrir las condiciones enumeradas en el art. 11 de la Orden de 9 de noviembre de 2005. 
nadas en la ley estatal. Tal es el caso de Andalucía donde, junto a aquéllas, se prevé la posible habilitación de las corporaciones locales ${ }^{103}$.

Sea como fuere, debe tenerse muy presente que tales entidades no asumen la tutela de los menores que corresponde, en todo caso, a la entidad pública, limitándose su papel al ejercicio de las funciones de guarda y mediación. Es decir, las entidades colaboradoras actúan por delegación de la Entidad Pública que las ha habilitado, que es la que mantiene la titularidad de las funciones ${ }^{104}$ (lo que es determinante a la hora de depurar responsabilidades) estando, pues, sometidas a las a las directrices, inspección y control de aquélla. Es importante insistir en este punto, pues la inexistencia de un control público riguroso, podría conducir a un inadecuado ejercicio su actividad en la que la protección de los derechos menores de ingresados no resultase debidamente garantizada.

\section{b) El convenio de colaboración}

El último requisito que debe concurrir para que la entidad pueda desempeñar las funciones de protección de menores que le reconoce la legislación de menores es la suscripción del correspondiente convenio de colaboración con la Administración (en el caso de Andalucía, la Consejería de Igualdad y Bienes$\operatorname{tar}$ Social).

La celebración este convenio entra de lleno en la actividad administrativa discrecional, no estando la Consejería obligada a celebrarlo ${ }^{105}$. En todo caso,

103 Art. 2 de la Orden de 9 de noviembre de 2005 (BOJA núm. 222, de 14 de noviembre), que regula la cooperación entre la Consejería y las entidades colaboradoras en el acogimiento residencial en Centros de Protección de Menores.

${ }^{104}$ Como señala REBOLLEDO VARELA, A. L. (1993), pág. 364, ello implica que "es la entidad pública quien ostenta por Ministerio de la Ley la tutela de los menores desamparados y la única que puede apreciar y calificar la situación de desamparo de un menor, quien tiene la iniciativa sobre adopción y el acogimiento y la única que puede realizar la propuesta de adopción prevista en el artículo 176.2 y seleccionar al eventual adoptante en el expediente previo (...) así como prestar su consentimiento en al acogimiento (...), de tal manera que las Instituciones Colaboradoras, no sólo no ostentan tales funciones, sino que tampoco pueden ejercerlas en modo alguno, siendo tal intromisión una infracción de las normas legales que habría de dar lugar a la privación de la habilitación". En el mismo sentido vid., vid. BARBER CÁRCAMO, R. (2002): "La subversión constitucional del acogimiento de menores", (Ref. Avanzadi BIB 2002\2169).

${ }^{105}$ El contenido de este convenio se especifica en el artículo 13.2 del Decreto 254/2001, de 20 de noviembre, que aprueba el Reglamento de procedimiento para la concesión de subvenciones en Andalucía. 
su suscripción se subordina a la previa emisión de un informe favorable de la Dirección General de Infancia y Familias ${ }^{106}$, informe que, por tanto, tiene carácter obstativo.

\section{RÉGIMEN SANCIONADOR}

\subsection{La inspección de los centros}

La actividad administrativa de inspección resulta indispensable para asegurar que los centros de menores cumplen todos los requisitos y actúan de conformidad con las previsiones legalmente previstas. Como señala FERNÁNDEZ RAMOS ${ }^{107}$, si esta función es indispensable en el ámbito de los servicios sociales en general, más lo es cuando se trata de colectivos especialmente frágiles como los ancianos o, en el caso que nos ocupa, la infancia ${ }^{108}$.

A pesar su trascendencia esta función no ha venido recibiendo la importancia que merece, por lo que el propio Defensor del Pueblo ${ }^{109}$ ha instado a las Administraciones Públicas para que, de conformidad con lo dispuesto en el artículo 21 de la LOPM, ejerzan las obligaciones que le corresponden a fin de asegurar la protección de los derechos de los menores a través de la inspección y supervisión de todos los centros en los que se encuentren acogidos menores de edad, obligación que - añade- deberá ejercerse con especial intensidad

${ }^{106} \mathrm{El}$ artículo 11 de la Orden de 9 de noviembre de 2005 establece los requisitos que deben concurrir para que el informe sea favorable. Son los siguientes:

a) Que la entidad y el centro cumplan con todos los requisitos legales, materiales y funcionales, contemplados en esta Orden.

b) Que exista disponibilidad presupuestaria.

c) Que se hayan presentado, comprobado y aprobado cada uno de los extremos derivados del tipo de programa o programas a desarrollar por el centro: Documentos técnicos, personal...

d) Que desde la Dirección General de Infancia y Familias se haya considerado necesaria la existencia del centro.

${ }^{107}$ FERNÁNDEZ RAMOS, S. (2007), pág. 63.

${ }^{108}$ En el Informe de 2009 del Defensor del Menor de Andalucía insiste en la necesidad de hacer un esfuerzo para articular las vías de reclamación previstas en el Decreto 355/2003 de 16 de diciembre, en cuyo artículo 16 se prevé que los menores acogidos en los Centros de protección y sus familiares tendrán derecho a exponer su disconformidad acerca de cualquier aspecto de la atención residencial, incluido el trato recibido del personal, así como a recibir una contestación expresa al caso planteado.

${ }^{109}$ DEFENSOR DEL PUEBLO (2009), pág. 401. 
cuando se trate de los centros dedicados a la atención a menores con problemas de conducta, tanto en lo que se refiere a la frecuencia de las inspecciones, como a su profundidad, atendiendo a las especiales necesidades y vulnerabilidad de estos menores ${ }^{110}$.

No existe en Andalucía ninguna norma en la que se recojan previsiones específicas sobre la inspección de los centros de menores. Debe estarse, por tanto, a lo dispuesto en el Decreto 396/2008, de 24 de junio, que aprueba Reglamento de Organización y Funcionamiento de la Inspección de Servicios Sociales de la Junta de Andalucía. Conforme al mismo, corresponde a la Inspección-órgano dependiente de la Consejería de Igualdad y Bienestar Social- colaborar en el buen funcionamiento del Sistema de Servicios Sociales, garantizar los derechos de las personas usuarias y promover la mejora continua del nivel de calidad en la prestación de los servicios sociales en esta Comunidad (art. 1 del Decreto 396/2008)

En aplicación de lo dispuesto en dicho Decreto -y antes en el 141/1999, de 8 de junio- se han aprobado diversos planes generales de inspección. El último - aún en vigor para el cuatrienio 2009-2010- ha sido aprobado por Orden de 18 de diciembre de 2008.

\subsection{Infracciones y sanciones}

La LMA no contiene una regulación exhaustiva del régimen de infracciones y sanciones referido a los centros de protección de menores ni sobre la forma en la que la potestad sancionadora debe ejercerse. Por tanto, debe estarse a lo dispuesto en el Decreto 355/2003, que aprueba el reglamento sobre Acogimiento Residencial de Menores y en el Reglamento Marco de Organización. De la lectura comparada de estas normas, resultan tres grandes grupos según que las infracciones resulten imputables al propio centro o su personal (afecten o no a los menores), a los menores ingresados y, por último, a sus padres o tutores.

En relación con las infracciones de los menores ingresados, interesa recordar el papel fundamental que juega el Reglamento de Organización como instrumento de garantía sus derechos. Como se anticipaba, éste se redactará de

${ }^{110}$ El Anteproyecto de Ley Orgánica complementaria al Anteproyecto de Ley de Actualización de la legislación sobre protección a la infancia, propone la introducción de un nuevo capítulo en la LOPM en el que se regula el ingreso y el régimen de estos menores en un centro de este tipo. 
conformidad con los principios y orientaciones recogidos en el Reglamento Marco, especificando las conductas que suponen alteraciones menos graves, graves y muy graves de la convivencia. En este sentido, es interesante destacar el cambio de modelo que-en la línea iniciada por Decreto 355/2003-impulsa el Reglamento Marco, al prever la sustitución del sistema tradicional, construido sobre la base de medidas represivas, por un sistema preventivo basado en el refuerzo de conductas positivas que en ningún caso podrá implicar la adopción de medidas que supongan directa o indirectamente castigos corporales, maltrato psíquico, privación de la alimentación o del descanso, del derecho a las relaciones personales, a la educación obligatoria o de asistencia al centro escolar, ni atentar contra la dignidad del menor mediante acciones que conduzcan a su humillación o ridiculización ${ }^{111}$ o la expulsión del menor de un centro.

Por lo demás, para la aplicación de las medidas correctivas deberá observarse el principio de proporcionalidad, de manera que éstas sean adecuadas a la edad y madurez de cada menor ${ }^{112}$. El Reglamento de Organización debe es-

111 Se consideran conductas especialmente perjudiciales para la convivencia, además de las previstas en art. 39 del Decreto 355/2003, las siguientes: introducir o poseer armas; participar en desórdenes colectivos o haber instigado a realizarlos en el caso de que se hayan producido; facilitar la ausencia del centro; resistirse de manera activa y grave al cumplimiento de las indicaciones del personal del centro en el ejercicio legítimo de sus atribuciones.

${ }^{112}$ Para la aplicación de las medidas educativas correctoras se tendrán en cuenta los siguientes criterios:

a) La edad.

b) La situación personal, social y familiar.

c) El Proyecto Educativo Individual.

d) El Plan de Intervención.

e) La perturbación del funcionamiento del centro y los perjuicios causados a las demás personas residentes.

f) El carácter educativo y recuperador, no meramente sancionador, de la corrección.

A efectos de la graduación de las correcciones, se tendrá en cuenta lo siguiente:

1. Son circunstancias paliativas:

a) El reconocimiento espontáneo de la conducta incorrecta y la petición de excusas.

b) La reparación del daño producido.

c) La falta de intencionalidad.

d) El mantenimiento de una conducta habitual positiva y favorecedora de la convivencia.

2. Son circunstancias intensificadoras:

a) La premeditación y la reiteración.

b) Causar daño, injuria u ofensa a los compañeros y compañeras de menor edad o a quienes se hayan incorporado recientemente al centro.

c) Cualquier acto que fomente la violencia, la discriminación, el racismo, la xenofobia o la incitación colectiva al incumplimiento de las normas de convivencia. 
pecificar qué tipo de medida de corrección será de aplicación en función del tipo de alteración de las normas de convivencia del mismo, con indicación de quién las aplica, en qué condiciones, la duración de las mismas y cualquier otra información al respecto.

\section{REFLEXIÓN FINAL}

A lo largo de las páginas que preceden, se han planteado alguno de los problemas que surgen en relación con los centros de menores. En ellas, se ha dejado constancia del notable retraso con el que el legislador ha afrontado la regulación jurídico administrativa de los mismos. A pesar de las críticas que esta demora merece, no puede dejar de subrayarse, como dato favorable, la existencia en Andalucía de un importante y completo entramado normativo tejido por normas de distinta jerarquía que ofrece una detalladísima regulación de los requisitos que deben reunir los centros de menores y en el que se contemplan variados aspectos de su organización administrativa, previsiones que en ocasiones deben completarse con las contenidas en la normativa estatal sobre servicios sociales.

A raíz del Informe especial del Defensor del Pueblo, se ha considerado oportuno realizar una aproximación al marco normativo regulador de estos centros para conocer si en él se contienen las previsiones adecuadas para la protección de los derechos de los menores ingresados. En este proceso, se ha se ha podido apreciar la evolución que ha experimentado su propio concepto, siendo el propósito del legislador el que éstos reproduzcan, en la medida de lo posible, la estructura de una familia tradicional y, lejos, por tanto, de los antiguos orfanatos o casas de expósitos. Las carencias denunciadas en el citado informe, han impulsado una modificación de la normativa estatal sobre menores con el fin de corregir ciertos aspectos y completar o profundizar en otros, encontrándose en tramitación dos proyectos en los que se recogen importantes avances y novedades, en particular, respecto de los centros de menores en situación de conflicto social.

Por otra parte, sin perjuicio de reconocer la conveniencia de hacer prevalecer el acogimiento familiar sobre el residencial, es indudable que los centros de menores son necesarios ya que sin ellos la Administración no podría cumplir las funciones que le corresponden en la protección de la infancia. Una cosa es que aquella fórmula sea la más adecuada y, otra muy distinta, es que esa opción pueda ser la única considerada. En ello influyen diversos factores entre los que se encuentran el menor calado en España -frente a otros países como 
el Reino Unido- de la filosofía del acogimiento, o las escasas ventajas económicas de que gozan las familias acogedoras. Es una realidad que, a día de hoy, el número de menores ingresados supera notablemente, al de los acogidos en familias. No obstante, el empeño en hacer prevalecer el acogimiento familiar sobre el residencial ha llevado a plantear la supresión gradual de la medida para siendo el propósito el fin de evitar que los más pequeños sean institucionalizados. Como es evidente, se trata de una fórmula cuyo éxito depende de la disponibilidad de familias acogedoras, por lo que dependerá de la consideración de nuevos modelos de acogimiento familiar como el "profesionalizado" o "especializado" así como la implicación de la Administración en el desarrollo de campañas de difusión y captación de familias.

Por lo que a los centros de protección se refiere, es importante destacar el papel crucial que, junto a la Administración, juega el sector privado, siendo mucho más numerosos los centros colaboradores que los públicos. El delicado papel que juegan tales centros, conduce, directamente, a la consideración de los requisitos que estas entidades deben reunir para poder ejercer las funciones que le son delegadas y al papel de control ex ante y ex post que la Administración debe jugar impidiendo la mercantilización de su actividad y garantizando la protección de los internos.

La necesidad de establecer un marco común que asegure un nivel de protección homogéneo de los menores ingresados en cualquier centro de protección, aconseja la fijación de un marco estatal de referencia en el que se contengan la regulación básica sobre régimen interior, infracciones y sanciones, tratamientos médicos, etc.

Por último, este estudio se ha realizado desde el reconocimiento de la imposibilidad de agotar todos los temas que se plantean en relación con el papel de la Administración en la protección de los menores desamparados. La pluralidad de problemas que emergen al hilo del mismo, anticipan la más que posible futura profundización en esta materia que, aunque inexplorada, empieza a ser - por fortuna-objeto de consideración por la doctrina administrativa.

\section{BIBLIOGRAFÍA CITADA}

ALEMÁN BRACHO, C. (2005): "La familia, prestadora y destinataria de prestaciones", Documentación Administrativa núm. 271-272, págs. 237-268.

BARBER CÁRCAMO, R. (2002): "La subversión constitucional del acogimiento de menores" (Ref. Aranzadi BIB 2002\2169). 
BENITO ALONSO, F. (2001): "Actuaciones frente a situaciones de riesgo y desamparo de menores: la tutela por ministerio de la Ley y guarda" (Ref. La Ley $11848 / 2001$ ).

BRAVO, A. y DEL VALLE F. J. (2009): "Crisis y revisión del acogimiento residencial y su papel en la protección infantil”, Papeles del Psicólogo, Vol. 30 (I), págs. 42-52.

GORRAL GARCÍA, E. (2003): "El derecho a la integridad moral del menor como fundamento de la imposibilidad de la reinserción en su familia" (Ref. Aranzadi BIB 2003\1118).

DE DIOS VIÉITEZ, M ${ }^{a}$ V. (2007): "Asistencia social y legislación civil en el ámbito de la protección de menores", Revista Furídica de Navarra núm. 43, págs. 167-182.

DEFENSOR DEL PUEBLO (2009): Informes, Estudios y Documentos. Centros de protección de menores con trastornos de conducta y en situación de dificultad social. Disponible a texto completo en http://www.defensordelpueblo.es/index.asp?destino=informes2.asp

DEFENSOR DEL MENOR DE ANDALUCÍA (1999): Informe Especial: Sistema de protección de menores y acogimiento residencia. Tomo I. Disponible a texto completo en http://www.defensor-and.es/informes_y_publicaciones/informes_estudios_y_resoluciones/informes_defensor_del_m enor/informe_0000/descargas/TOMO1.DOC.

DE PABLO CONTRERAS, P. (1993): "Comentario al artículo 172 del Código Civil”, en BERCOVITZ RODRÍGUEZ CANO, R., (Coord.), Comentarios a las reformas del Código Civil. Tecnos, Madrid, págs. 35-88.

DE PALMA DEL TESO, A. (2006): Administraciones públicas y protección de la infancia. INAP, Madrid.

DE PALMA DEL TESO, A. (2004): "El derecho de los menores a la asistencia y protección de las Administraciones Públicas. Las competencias locales en materia de protección de menores", Cuadernos de Derecho Local núm. 4, págs. 103-138.

Dirección General de Familias y la Infancia (2009): Boletín Estadístico de Protección a la Infancia.

EGEA FERNÁNDEZ, J. (1993): "Comentario al artículo 173 del Código Civil”, en BERCOVITZ RODRÍGUEZ-CANO, R. (Coord,), Comentarios a las reformas del Código Civil. Tecnos, Madrid, págs. 88-111.

ESGRIBANO TORTAJADA, P. (2009): "Los conceptos de desamparo y situaciones de riesgo desde la perspectiva de nuestros Tribunales" (Ref. La Ley 12142/2009).

ESPIAU ESPIAU, S. (1999): "La situación de desamparo y las medidas de protección", en ESPIAU ESPIAU, S. y VAQUER ALOY, A. (Eds.), Protección de menores, acogimiento y adopción. Marcial Pons, Madrid, págs. 71-86. 
FERNÁNDEZ MASÍA, E. (2001):“Las entidades públicas y la protección de los menores extranjeros en España", (Ref. La Ley 1642/2001).

FERNÁNDEZ RAMOS, S. (2007): "Los centros residenciales para personas mayores, especial referencia a Andalucía", Revista Andaluza de Administración Pública núm. 67, págs. 11-86.

GARCÍA DE ENTERRÍA y FERNÁNDEZ, Curso de Derecho administrativo (1993). Civitas, Madrid.

LLEBARIA SAMPER, S. (1990): Tutela automática, guarda y acogimiento de menores. Bosch, Barcelona.

MARTÍNEZ PIERA, E. (2010): "Reflexiones en torno a la intervención de los poderes públicos para la protección e inserción de los menores" (Ref. La Ley 7976/2010).

MURILLAS ESGUDERO, J. M. (2003): "Notas a la Ley 4/1998, de 18 de marzo, del Menor, de la Comunidad Autónoma de la Rioja" (Ref. Aranzadi BIB 2003\418).

OCAÑA RODRÍGUEZ, A. (2006): "En busca de una más adecuada regulación del régimen de protección de menores", Abogados de Familia (Ref. La Ley 1008/2006).

PALOMINO DÍEZ, I. (2005): "La discutida naturaleza de la tutela de las entidades públicas del artículo 172.1 del Código Civil" (Ref. La Ley 1295/2005).

REBOLLEDO VARELA, A. L. (1993): Comentario a la Disposición adicional $1^{a}$ de la Ley 21/1987, de 11 de noviembre, en BERCOVITZ RODRÍGUEZ-CANO, R. (Coord.), Comentarios a las reformas del Código Civil. Tecnos, Madrid, págs. 350-366.

SÁINZ-CANTERO CAPARRÓS, Ma B. y PARDO MARTÍNEZ, E. (2010): Régimen jurídico de los centros de protección y reforma de menores. Comares, Granada.

RODRÍGUEZ SOL, L. (2001): "La protección y acogimiento de menores en el Derecho español", (Ref. La Ley 13787/2001).

TOLIVAR ALAS, L. (1991): "Aspectos jurídico-administrativos de la protección de menores", RAP núm. 124, págs. 35-63.

VILLA RUBIO, M. (1999): "Protección de menores desamparados", en ESPIAU ESPIAU, S. y VAQUER ALOY, A., (Eds.), Protección de menores, acogimiento y adopción. Marcial Pons, Madrid, págs. 48-69.

VILLAR ROJAS, F. J. (2005): "Formas de gestión de los servicios sociales. En particular, la vinculación de gestores privados al sistema público mediante conciertos y convenios", Documentación Administrativa núm. 271-272, págs. 389-412.

VARGAS CABRERA, B. (1994): La protección de menores en el ordenamiento jurídico. Comares, Granada.

VIVANGOS SÁNCHEZ, M. (2001): "Constitución de la tutela automática tras la declaración de desamparo (Ref. La Ley 1959/2001). 